\title{
PENGARUH TEKNIK MASASE COUNTER PRESSURE TERHADAP INTENSITAS PENURUNAN NYERI PERSALINAN KALA 1 FASE AKTIF DI BPM HERASDIANA
}

\author{
${ }^{1}$ Selvy Apriani, ${ }^{2}$ Enderia Sari \\ ${ }^{1,2}$ Fakultas ilmu Kesehatan Program studi D III Kebidanan, Institut Ilmu Kesehatan dan Teknologi \\ Muhammadiyah Palembang \\ ${ }^{1)}$ selvy.apriani.26@gmail.com, ${ }^{2)}$ sarienderia@gmail.com
}

\begin{abstract}
ABSTRAK
Proses persalinan merupakan rangkaian yang pasti dilalui oleh setiap ibu hamil, nyeri pada saat persalinan merupakan kondisi fisiologis yang secara alami dialami oleh hampir semua ibu bersalin. Manajemen nyeri persalinan dapat diterapkan secara non farmakologis seperti relaksasi dan masase. Persalinan lama penyebab utama kesakitan ibu selama persalinan, nyeri persalinan dapat dikelola melalui penanganan nyeri yang tepat salah satunya dengan teknik masase counter pressure. Tujuan penelitian ini untuk mengetahui intensitas nyeri persalinan sebelum dan setelah dilakukan masase counter pressure serta pengaruh teknik masase counter pressure. Metode penelitian yang digunakan adalah quasi eksperiment, desain satu kelompok pre dan post test. Teknik penelitian menggunakan observasi partisipatif, yaitu melakukan pengukuran intensitas nyeri dan melakukan tindakan teknik masase counter pressure. Sample penelitian adalah ibu bersalian yang berda dalam kala I fase aktif, berjumlah 30 orang dengan teknik pengambilan sample total sampling. Dari hasil penelitian didapatkan bahwa rata-rata nyeri sebelum masase counter pressure 7,27 dengan standar deviasi 691. Pada responden yang telah dilakukan teknik masase counter pressure rata-rata nyeri persalinan adalah 5,47 dengan standar deviasi 819 . Terlihat nilai mean perbedaan antara nyeri sebelum dan sesudah teknik masase counter pressure adalah 1800 dengan standar deviasi 887. Hasil uji statistik didapatkan nilai $\mathrm{p}=0,0001$ maka dapat disimpulkan ada perbedaan yang significan rata-rata intensitas penurunan nyeri sebelum dan sesudah dilakukan teknik masase counter pressure. Kesimpulan terdapat pengaruh teknik masase counter pressure terhadap penurunan intensitas persalinan normal. Teknik masase counter pressure dapat diterapkan oleh bidan dalam melakukan asuhan intranatal, dapat dimasukan dalam protap penatalaksanaan nyeri persalinan.

Kata Kunci : Nyeri persalinan, Teknik masase counter pressure.
\end{abstract}

\section{ABSTRACT}

The process is a series that every pregnant woman goes through, Pain during labor is a physiological condition that is naturally experienced by almost all mothers in labor. Management of labor pain can be applied non-pharmacologically such as relaxation and massage. Long labor is the main cause of maternal pain during labor, labor pain can be managed through proper pain management, one of which is counter pressure massage technique. The purpose of this study was to determine the intensity of labor pain before and after counter pressure massage and the effect of counter pressure massage techniques. The research technique uses participatory observation, namely measuring pain intensity and performing counter pressure massage techniques The research sample is pregnant women who are in the first stage of the active phase, totaling 30 people with total sampling technique From the results of the study, it was found that the average pain before massage counter pressure was 7.27 with a standard deviation of 691 In respondents who have done counter pressure massage technique the average labor pain is 5.47 with a standard deviation of 819. It can be seen that the mean value of the difference between pain before and after the counter pressure massage technique is 1800 with a standard deviation of 887 . The results of statistical tests obtained $p$ value $=$ 
0.0001 , it can be concluded that there is a significant difference in the average intensity of pain reduction before and after the counter pressure massage technique is performed. The conclusion is that there is an effect of counter pressure massage technique on decreasing the intensity of normal labor. The counter pressure massage technique can be applied by midwives in carrying out intranatal care, it can be included in the procedure for managing labor pain.

Keywords: labor pain, counter pressure massage technique.

\section{PENDAHULUAN}

Persalinan merupakan suatu proses alamiah yang akan dilalui oleh setiap ibu hamil. Pada proses ini terjadi peregangan dan pelebaran mulut rahim sebagai akibat dari kontraksi otot-otot rahim untuk mendorong bayi keluar. Bersamaan dengan setiap kontraksi, hal inilah yang menyebabkan nyeri pada persalinan (Danuatmaja \& Meilisari, 2008).

Nyeri pada saat persalinan merupakan kondisi fisiologis yang secara universal dialami oleh hampir semua ibu bersalin. Menurut Danuatmaja dan Meilasari (2008) saat yang paling melelahkan dan berat, kebanyakan ibu mulai merasakan sakit atau nyeri pada saat persalinan adalah pada kala I fase aktif. Dalam fase ini kebanyakan ibu merasakan sakit yang hebat karena kegiatan rahim mulai lebih aktif. Pada fase ini kontraksi semakin lama semakin kuat dan semakin sering.

Berbagai cara dilakukan untuk menurunkan intensitas nyeri, yaitu dengan menggunakan metode farmakologi dan non farmakologi. Manajemen nyeri secara farmakologi memang lebih efektif dibandingkan dengan metode non farmakologi namun metode farmakologi lebih mahal dan berpotensi mempunyai efek yang kurang baik pada ibu dan janin, sedangkan metode non farmakologi bersifat noninstrusif, noninvasive, murah, simple, dan tanpa adanya efek yang merugikan (Prasetyo, 2010).

Tindakan peredaan nyeri secara non farmakologi yang dapat dilakukan Penelitian ini bertujuan untuk Mengetahui pengaruh teknik masase counter pressure terhadap penurunan intensitas nyeri persalinan kala I fase aktif di BPM Herasdiana Palembang dengan Asuhan Holistic secara menyeluruh salah satu upaya yang dapat dilakukan dengan Conter Pressurre agar menurunkan tingkat nyeri persalinan kala 1 pada ibu bersalin, pijatan yang dilakukan dengan memberikan tekanan yang terus menerus selama kontraksi pada tulang sakrum pasien dengan pangkal atau kepalaan salah satu telapak tangan, tekanan dalam massage counter pressure dapat diberikan dalam gerakan lurus atau lingkaran kecil teknik ini efektif menghilangkan sakit punggung akibat persalinan, namun perlu disadari bahwa ada ibu yang tidak bisa dipijat bahkan disentuh saat mengalami kontraksi. (Danuatmadja dan Meilasari, 2008).

Berdasarkan hasil penelitian pada Jurnal Ilmiah Bidan mengenai Efektifitas Counter pressure Terhadap Penurunan Intensitas Nyeri Kala I Fase Aktif Persalinan Normal tahun 2014. Nyeri persalinan sebelum dilakukan masase counterpressure berada pada skala 9-10 (100\%) dan setelah dilakukan masase counterpressure nyeri menurun paling besar pada skala 3-6 sebanyak 13 responden $(86,7 \%)$. Analisa data menunjukkan signifikansi lebih kecil dari $5 \%$ counter pressure efektif untuk menurunkan intensitas nyeri kala I fase aktif persalinan normal (Jidan, 2014). Berdasarkan penjelasan diatas penulis tertarik untuk meneliti pengaruh teknik masase counter pressure terhadap penurunan intensitas nyeri pada ibu bersalin kala I fase aktif di BPM Herasdiana Palembang.

\section{METODE PENELITIAN}

Metode penelitian ini adalah kuasi eksperimen dengan pendekatan the one group pretest - posttest design. 
Populasi pada penelitian ini adalah semua ibu bersalin kala satu fase aktif di BPM Herasdiana. Metode pengambilan sampel yang digunakan dalam penelitian ini adalah Total sampling Penyajian data univariat di sajikan dalam bentuk distribusi frekuensi dan persentase untuk mengetahui pengaruh masase counter pressure terhadap intensitas penurunan nyeri dilakukan uji $T$ dependen

\section{HASIL dan PEMBAHASAN}

Tabel 1 Distribusi frekuensi Intensitas Nyeri Sebelum dilakukan Masase Counter Pressure pada kala 1 fase aktif

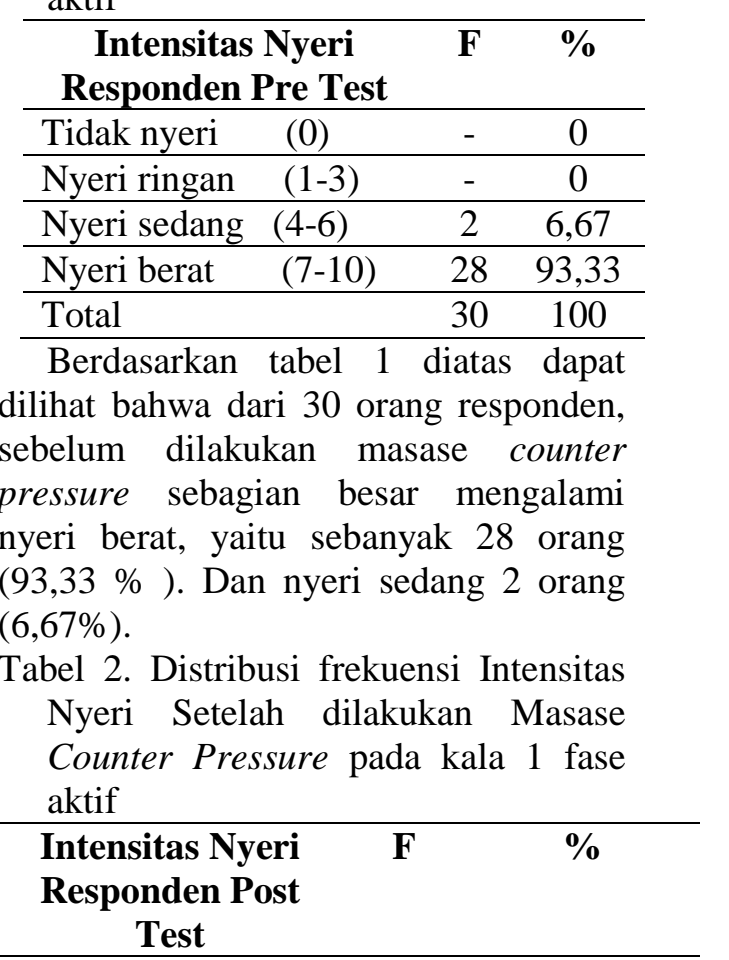

\begin{tabular}{lccc}
\hline Tidak nyeri $(0)$ & - & 0 \\
\hline Nyeri ringan $(1-3)$ & - & 0 \\
\hline Nyeri sedang (4-6) & 26 & 86,67 \\
\hline Nyeri berat $\quad(7-$ & 4 & 13,33
\end{tabular}
10)

\begin{tabular}{lll}
\hline Total & 30 & 100 \\
\hline Berdasarkan tabel 2 & diatas & dapat
\end{tabular}
dilihat bahwa dari 30 orang responden, sesudah dilakukan masase conter pressure sebagian besar mengalami penurunan nyeri menjadi nyeri sedang diperoleh 26 orang $(86,67 \%)$ dan diperoleh 4 orang $(13,33 \%)$ mengalami nyeri berat.

Tabel 3 Distribusi Rata-rata intensitas penurunan nyeri menurut pengukuran sebelum dan sesudah diakukan teknik masase counter pressure.

\begin{tabular}{rrrrrrl}
\hline Variabel & Mean & SD & SE & P.value & N \\
& & & & & \\
\hline Sebelum & 7,27 & 691 & 126 & & \\
& & & & 0,0001 & 30 \\
Sesudah & 5,47 & 8,19 & 150 & & \\
\hline Dari & hasil & penelitian didapatkan &
\end{tabular}

bahwa rata-rata nyeri sebelum masase counter pressure 7,27 dengan standar deviasi 691. Pada responden yang telah dilakukan teknik masase counter pressure rata-rata nyeri persalinan adalah 5,47 dengan standar deviasi 819. Terlihat nilai mean perbedaan antara skala nyeri persalinan kala I fase aktif sebelum dan sesudah teknik masase couter pressure adalah 1800 dengan standar deviasi 887. Hasil uji statistik didapatkan nilai $\mathrm{p}=0,0001$ artinya terdapat perbedaan yang signifikan ratarata intensitas nyeri persalinan kala I fase aktif pada primigravida sebelum dan sesudah dilakukan teknik masase counter pressure.

Berdasarkan hasil analisa deskriptif, intensitas nyeri sebelum dilakukan teknik masase counter pressure menunjukan bahwa sebagian bersar responden dengan keluhan nyeri berat yaitu $28(93,33 \%)$ responden dan nyeri sedang $2(6,67 \%)$ responden.

Nyeri adalah pengalaman sensori dan emosional yang tidak menyenangkan akibat kerusakan jaringan aktual dan potensial. Nyeri adalah alasan utama seseoranng mencari bantuan perawatan kesehatan (Smeltzer \& Bare, 2002).

Menurut Prawiroharjo (2008) bahwa nyeri persalinan merupakan suatu kondisi yang fisiologis. Secara fisiologis nyeri persalinan mulai timbul pada persalinan fase laten dan fase aktif, pada fase laten terjadi pembukaan servik sampai $3 \mathrm{~cm}$, bisa berlangsung selama 8 jam. Nyeri berasal dari kontraksi uterus dan dilatasi servik. Dengan makin 
bertambahnya baik volume maupun frekuensi kontraksi uterus, nyeri yang dirasakan akan bertambah kuat, puncak nyeri terjadi pada fase aktif, dimana pembukaan lengkap sampai $10 \mathrm{~cm}$ dan berlangsung selama 6 jam. Nyeri yang terjadi yang terjadi dapat mempengaruhi kondisi ibu berupa kelelahan, rasa takut, khawatir, ketidak nyamanan dan menimbulkan stress sehingga dapat menyebabkan melemahnya kontraksi rahim dan berakibat pada persalinan yang lama.

Nyeri terjadi akibat kerusakan jaringan yang dirasakan ibu inpartu kala I fase aktif. Situasi dan kondisi dalam menghadapi nyeri sangat individual,sehingga menyebabkan pengalaman rasa nyeri berbeda antara satu wanita dengan yang lain, demikian pula antara persalinan pertama dengan persalinan berikutnya (Stoppard, 2008).

Nyeri merupakan kondisi berupa perasaan yang tidak menyenangkan akibat dari rusaknya jaringan pada tubuh. Sifatnya sangat subyektif karena perasaan nyeri berbeda beda pada setiap orang dalam hal skala atau tingkatannya,dan hanya orang terseutlah yang dapat menjelaskan (Brunner \& Sudart, 2001).

Nyeri persalinan menurut Danuatmaja (2004), Merupakan rasa sakit yang terjadi akibat adanya aktivitas besar di dalam tubuh guna mengeluarkan bayi. Dimana rasa sakit kontraksi dimulai dari bagian bawah punggung kemudian menyebar ke bagian bawah perut, umumnya rasa sakit ini berbeda beda yang dirasakan setiap ibu.

Intensitas nyeri sebelum teknik mase counter pressure mempunyai interval dengan skala nyeri 5 sampai 8 . Berarti nyeri yang di rasakan oleh responden adalah nyeri sedang sampai berat. Hal ini di sebabkan karena pada fase aktif sebelum tindakan simpul saraf teraktivasi tanpa hambatan, oleh impuls nyeri dari uterus yang mengalami kontraksi dan serviks yang mengalami peregangan, kemudian impulls nyeri tersebut ditransmisi melalui segmen saraf spninalis Torakal 10,11,12 dan saraf torakal bawah serta saraf simpatik lumbal atas (L1) ke dalam kornu dorsalis medula.

Teori kontrol gerbang (Gate Control theory) Berdasarkan teori ini serabut syaraf mentranmisikan rasa nyeri ke spinal cord yang hasilnya dapat dimodifikasi di tingkat spinal cord sebelum di tranmisikan ke otak. Sinap sinap pada dorsal horn berlaku sebagai gate yang tertutup untuk menjaga impuls sebelum mencapai otak atau membuka untuk mengizin kan impuls naik ke otak. Teori gate control menyatakan bahwa selama proses persalinan impulls nyeri berjalan dari uterus sepanjang serat serat syaraf besar ke arah uterus ke subtansia gelatinosa didalam spinal kolumna, sel sel tranmisi memproyeksikan pesan nyeri ke otak. Adanya stimulasi (seperti Vibrasi, menggosok gosok atau masase) mengakibatkan pesan yang berlawanan ini menutup gate di substanti gelatinosa lalu memblokir pesan nyeri sehingga otak tidak mencatat pesan nyeri tersebut (Andromoyo, 2013).

Intensitas nyeri setelah dilakukan Teknik masase counter pressure mempunyai interval dengan skala nyeri 4-7, lebih kecil dari rata rata sebelum tindakan, kondisi tersebut karena impuls nyeri dari uterus yang mengalami kontraksi dan servik yang mengalami peregangan dihantar sepanjang saraf sensorik menuju ke otak, hanya sejumlah sensasi atau pesan tertentu dapat dihantar melalui jalur saraf ini pada saat bersamaan. Dengan memakai teknik masase counter pressure jalur saraf untuk persepsi nyeri ini dapat dihambat atau dikurangi, sehingga nyeri yang dirasakan berkurang.

Perbedaan Intensitas Nyeri Sebelum dan Sesudah Teknik Masase counter pressure. Penurunan rata-rata intensitas nyeri adalah 7,27 menjadi 5,47. Keberhasilan ini membuktikan bahwa dengan tekanan counter pressure dapat mencegah atau menghambat impuls nyeri yang berasal dari serviks dan korpus uteri dengan memakai landasan teori gate control. Sensai nyeri dihantar 
dari sepanjang saraf sesoris menuju ke otak, dan hanya sejumlah sensasi atau pesan tertentu dapat dihantar melalui jalur saraf ini pada saat bersamaan. Dengan memakai teknik masase jalur saraf untuk persepsi nyeri ini dapat dihambat dan dikurangi, lalu intensitas nyeri yang dirasakan ibu berkurang dan ketegangan tidak terjadi, sehingga kontraksi uterus yang tidak efektif akibat nyeri dapat dicegah, sehingga persalinan lama tidak terjadi.

\section{KESIMPULAN}

Ada pengaruh masase counter pressure terhadap penurunan intensitas nyeri persalinan dengan perbedaan nilai mean 1,800 (p value 0,0001). Penelitian Selanjutnya diharapapkan dapat mengkombinasi metode non farmakologi lainya dengan masase conter presur, untuk hasil yang lebih optimal dalam penatalaksanaan nyeri.

\section{Referensi}

Anita. (2018) . Pengaruh Akupresur Lo4 (he kuk) dan Thai Cong terhadap Tingkat Nyeri Persalinan Kala I pada Ibu Bersalin. Jurnal Kesehatan 9(3) : ISSN 2086-7751

Andarmoyo. (2013). Konsep dan Proses Keperawatan Nyeri. Jogjakarta : Ar-Rus Media

Ancheta. R, \& Simkin. P. (2005). Buku Saku Persalinan. Jakarta : EGC

Andarmoyo, Sulistyo dan Suharti. (2013). Persalinan Tanpa Nyeri Berlebih. Jogjakarta: Ar-Ruzz Media.

Anik Maryunani. (2010). Ilmu Kesehatan Anak. Jakarta : CV. Trans Info Media.

Bobak,I,M., Lowdermilk, D,L., Jensen, M,D. (2004). Buku ajar Keperawatan maternitas, Edisi 4, Alih Bahasa Maria A. Wijayanti. Petter I. Anugerah. Jakarta: EGC

Bobak IM, L. D., Jensen MD, Perry SE. (2012). Buku Ajar Keperawatan Maternitas
(Maternity Nursing). Jakarta: EGC.

Brunner \& Suddarth. (2001). Buku Ajar Keperawatan Medikal Bedah, edisi 8. Jakarta : EGC

Craven, R.F. \&Himle, C.J. (2000). Fundamentals of nursing: human health and function. (3 rd ed.). Philadelphia: J.B. Lippincott Company

Cunningham, Donald.J. (2004). Mind, Culture, and Activity .Indiana University. 2(1)

Chung, et al. (2012). Accupoin Stimulation Intervention For People With Primary Dysmenorrhea. Systematic Review and Meta-Analysis of Randozed Trials. PubMeD, 20 (05), 356-363

Danuatmaja, S., Meilasari, M. (2008) . Persalinan Normal Tanpa Rasa Saki. Puspa Swara. Jakarta.

Judha, M., Sudati., \& Fauziah, A. (2012). Teori Pengukuran Nyeri \& Nyeri Persalinan. Yogyakarta: Nuha Medika

Habananda T. (2004). Nonpharmacological pain relief in labor. J Med Assoc Thai. 87 (194-202).

Julie, Moore. (2012). Birthing Outcomes From An Australian Hypnobirthing Programe. British journal of midwifery 20 (8):558-564.

Kozier, Erb, Berman, \& Snyder. (2011). Buku Ajar Fundamental Keperawatan : Konsep, Proses \& Praktik (7 ed., Vol. I). Jakarta: EGC.

Ladewig, Patricia W. London, Marcia L dan Olds, Sally B. (2006). Asuhan keperawatan keperawatan Ibu-Bayi Baru Lahir. Jakata : ECG.

Lowdermilk. (2012). Pengaruh Massage Counterpressure Terhadap Intensitas Nyeri Persalinan Kala I Fase Aktif. Yogyakarta. Jurnal Kebidanan dan Keperawatan, 12(1) 
Mander, R (2003). Nyeri Persalinan. Jakarta: Penerbit Buku Kedokteran : EGC.

Mander. (2003). Nyeri Persalinan. Jakarta : EGC

Potter, dkk. (2009). Pengaruh Massage Counterpressure Terhadap Intensitas Nyeri Persalinan Kala I Fase Aktif. Yogyakarta. Jurnal Kebidanan dan Keperawatan. 12 (1)

Potter, Patricia A. (2005) . Buku Ajar Fundamental Keperawatan. Edisi 4.Jakarta : EGC

Potter \& Perry. (1997). Fundamental Keperawatan Konsep, Proses dan Praktik Volume 1. Jakarta : EGC
Prasetyo, S. N. (2010) . Konsep dan Proses Keperawatan Nyeri.Yogyakarta: Graha Ilmu

Prawirohardjo, Sarwono. (2008) . Ilmu Kebidanan Sarwono Prawirohardjo. Jakarta: PT. Bina Pustaka Sarwono Prawirohardjo

Smeltzer, S.C. \& Bare, B.G. (2013). Buku Ajar Keperawatan Medikal Bedah Brunner \& Suddarth, edisi 8. Jakarta : EGC.

Stoppard, M (2008). Buku pintar kehamilan dan persalinan modern, Yogyakarta : Quills Book Publishers. 